\title{
Urban Sprawl and Fertile Agricultural Lands in Iranian Cities - Case Study: Tehran and Karaj
}

\author{
Saeed Zanganeh Shahraki, Faranak Seifolddini and Ahmad Pourahmad \\ Department of Human Geography, University of Tehran, Tehran, Iran
}

\begin{abstract}
The phenomenon of disproportional expansion of urbanized areas into undeveloped area or "urban sprawl" has become a very a remarkable characteristic of urban development worldwide in the last decades. Urban sprawl is the popular media as the source of numerous social, environmental, and economic ills. One of the most evident consequences of urban sprawl is destroying agricultural lands around cities. One of the extreme expanded cities in Iran is Tehran megalopolis and cities around it. Tehran is expanding in all dimensions especially toward western side where Karaj city is located. The area of study for this research is Tehran and Karaj cities where the event of urban sprawl is happening. Materials used for achieving goal are aerial photographs, satellite images, thematic map of degree of soil and GIS software. The result of analysis shows that Tehran area has expanded from 10000 in 1956 to 80835 hectares in 2006. Area of Karaj city increased from 125 to 26000 hectare in the same period and the population density of two cities together decreased from 116 to 43 people per hectare. Sixty five percent of areas of these two cities are consisted of good fertile agricultural lands with irrigation potential. Twenty four percent of this land (14900 hectares) is classified as rank or class 1, 38.1 percent (23725 hectares) has rank 2, and 37.9 percent (23605) has rank 3 in terms of fertile land. Based on soil class and potential of production of wheat, it is estimated that if urban sprawl and expansion of these cities decreased or the direction of expansion changed to unfertile lands (class 4, 5 and 6), and the cultivation of land had continued, 270,000,000 kilos of wheat could be produced yearly. So, urban sprawl is seen as one of the potential challenge to urban sustainable development and cannot be urban sustainable form.
\end{abstract}

Key words: Urban sprawl, sustainable development, agricultural lands, land productivity, urban sustainable form.

\section{Introduction}

Debates on the urban form have become strongly polarized between the advocates and opponents of the compact and of the dispersed or "sprawled" city [1]. Nowadays, researchers are debating on the subject of urban form in order to find more effective and more sustainable urban form. Some of them believe that compactness and intensification in urban development has plenty of positive outcomes [2], so they propose that cities should develop more compact. Yet, some others believed that accessibility to more space and land for life has more attraction and benefits among residents. Consequently, this group of researchers suggests that compact city model has some adverse effects. Therefore, researchers of urban affairs and

Corresponding author: Faranak Seifolddini, associate professor, research fields: urban planning. E-mail: seifolddini_faranak@hotmail.com. urban planners still do not agree about which urban development model is more sustainable. It seems that the best way of knowing and recognition of urban sustainable form is to study and compare different positive and negative impacts of each model of urban development. Nevertheless, comparing all social, environmental and economic effects is both time consuming and costly work and it is a big job for one paper. Under this rationale, this paper is carrying out to study the effect of urban sprawl model on soil resources and agricultural lands. This work has difference importance: first, the most prominent negative impact of urban sprawl is change of environmental landscape and land use change [3], second, the dispersed urban form is gaining presence and therefore raising concerns about its potential negative and irreversible effects for urban sustainability in all countries, Iranian cities do not escape from this general trend [4-7]. Third, in a 
developing country like Iran that has lack of fertile agricultural lands in one hand, and has a very rapid urbanization process [8], in the other hand, it is required to study this issue more seriously. The case of two biggest cities in Tehran Metropolitan Area, TMA, (cities of Tehran and Karaj) is introduced in the following section with an aim of presenting an example of recent urban growth strongly influenced by the dispersed and sprawl model. Tehran metropolitan area (TMA) is located in a hillside region with productive cultivated lands. But over the past half a century, it experienced a drastic growth in both population and development. But, during the process of urbanization in this region, no planning for settling newcomers or immigrants has happened. As a result, thousands of hectares of agricultural lands converted to urban land uses during this period. But because this trend is not only decreasing but also progressive and also it is a problem of other Iranian cities, in this paper we studied it more in quantitative terms. To characterize urban sprawl in the Tehran Metropolitan Area, our study had the following objectives: to identify spatial spread patterns of built-up land expansion from the urban core and associated landscape effects; to determine land use changes in urban fringes and outskirt especially between urban and agricultural land uses, to determine soil class of lands destroyed because of sprawl pattern and finally to give a brief discussion about urban sustainable form. To address these objectives, remote sensing images, aerial photography, geographic information system and some secondary data and maps from urban organization are used.

\section{Study Area}

The study area comprises two biggest cities of Tehran Metropolitan Area (TMA), i.e., Tehran, capital city and city of Karaj combined. This metropolitan area lies on the southern foot of Alborz mountain range in a vast area between dessert and mounts from $51^{\circ}, 4^{\prime} \mathrm{E}$ to $52^{\circ}, 00^{\prime} \mathrm{E}$ and from $33^{\circ}, 35^{\prime} \mathrm{N}$ to $35^{\circ}, 55^{\prime} \mathrm{N}$ (Fig. 1). The reasons of selection of these two cities together for study and analysis are that at first Karaj was a very small town and it grew just because of locating close to Tehran. Moreover, the next growth and development of Tehran undoubtedly will be in the west, where Karaj is located. Hence, in the near future these two cities will attach and will become a very big metropolis.

Because of the population and economic growth, the region has experienced significant alteration of its natural landscapes as its urban built-up land increases. However, there is a lack of knowledge of amount and type of agricultural lands converted to urban land uses which hinders a comprehensive understanding of urban sprawl patterns and informed urban planning in the metropolitan area.

\section{Methodology}

Since the built-up is generally considered as the parameter for quantifying urban sprawl [9-11], this parameter is used to detect borders of cities. In order to analyze the urban growth pattern of the TMA between 1955 and 2001, two possible materials, aerial photography of metropolitan area in year 1955 and landsat image of 2001 are used. In our case, visual interpretation was clearly the best method to avoid a huge number of misclassifications. This method is considered the best way to capture information regarding urban trends [12] and makes possible the identification of relevant characteristics which are better distinguished by their visual form and pattern rather than by their spectral signal [13]. Two maps from aerial photography and satellite image delimit urban from non-urban land covers through a photo-interpretation process and manual digitalization of high resolution digital color aerial photography on the computer screen. All of the processing work was done on Arc GIS 9.2. Preprocessing of the satellite images using a geometric correction technique was first carried out on the images before they could be used. The next step after detecting urban sprawl pattern in study area over about five past decades is to determine the class of soil resources and lands changed 


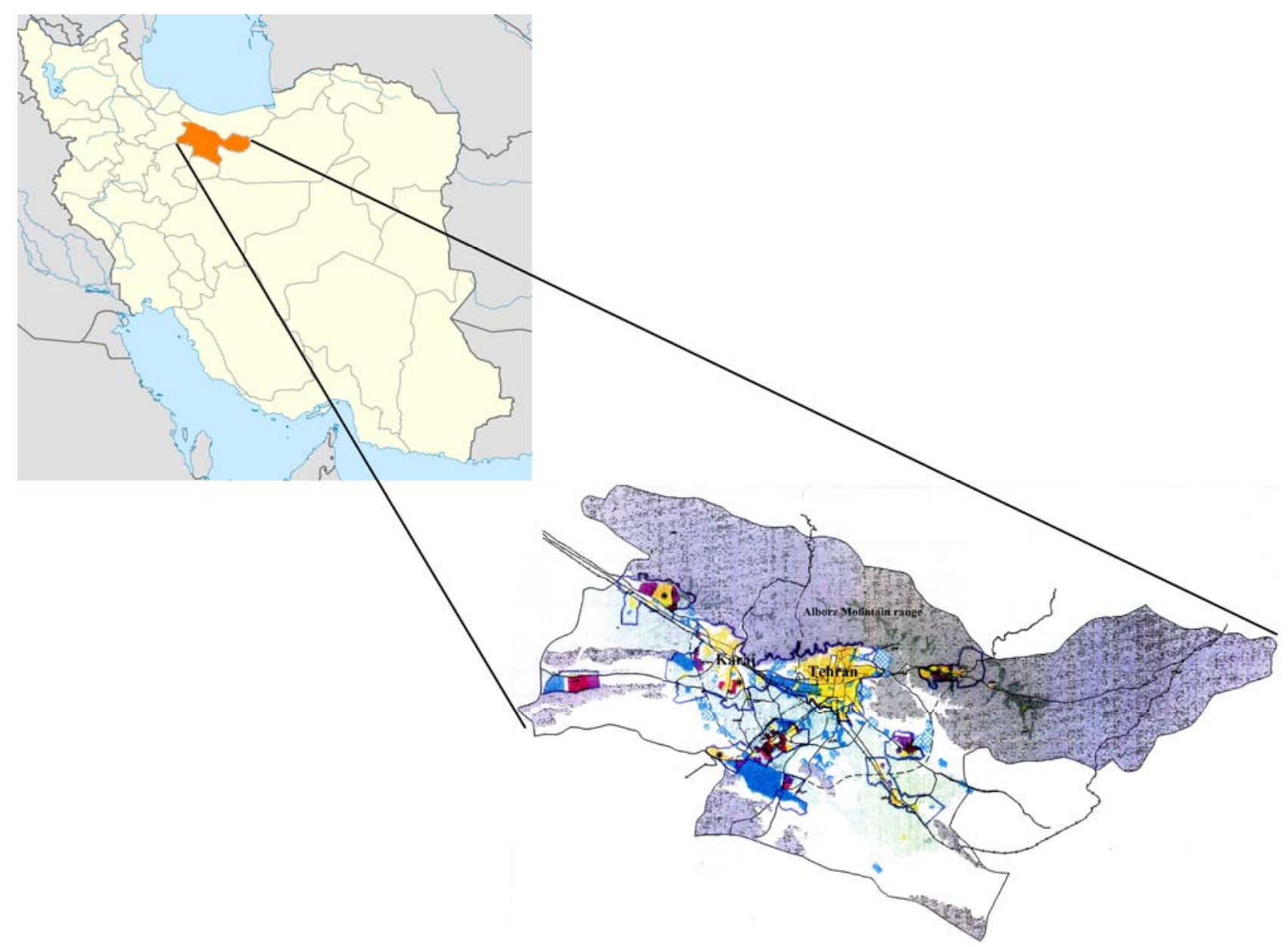

Fig. 1 The map of study area.

from any land uses to urban land uses. For this aim, map of pedology or soil classification map prepared by Iranian Institute of Water and Soil (2005) [14] were used (Table 1). This map also converted into vector format in Arc GIS for quantification purposes. According to maps published by Iranian Institute of Water and Soil, there are 6 categories of soil class. These categories are based on some factors like soil formation, morphology, classification, slope, and etc.

\section{Results}

\subsection{Tehran}

City expansion in Tehran until 1955 was high-density development. In that time agricultural land has rarely converted to urban uses and cultivation structure was very active around this city. As it is shown in Fig. 2, in 1955, physical expansion and
Table 1 Soil classes and their description.

\begin{tabular}{|c|l|}
\hline Soil class & \multicolumn{1}{|c|}{ Description } \\
\hline I & land without any limitation for cultivation \\
\hline II & land with partial limitations for cultivation \\
\hline III & land with medium limitations for cultivation \\
\hline IV & $\begin{array}{l}\text { land with harsh and drastic limitations for } \\
\text { cultivation }\end{array}$ \\
\hline V & $\begin{array}{l}\text { land with terrible limitations such as salinity, alkali } \\
\text { and underground water for cultivation }\end{array}$ \\
\hline VI & Barren land and wasteland \\
\hline
\end{tabular}

development was around the city center, with a continuous pattern and not detached and disjointed growth and entire new neighborhoods were built at the edge of traditional city to accommodate the increasing population migrating from rural areas to the city. Tehran built-up area has been 10000 hectares in 1955 . There were many farming lands in all direction particularly in the south and west and gardens in the 
north of city. But, this trend has changed in the next periods as one can see in the Fig. 2. Thus, after nearly half a century, from 1955 to 2001, urban land increased very rapidly in the region. Whole land occupied by Tehran in 2001 is 80835 hectares. Some 70835 new hectares have become "urban" during this period. The rate of development of land in Tehran, is outstripping the rate of population growth, since population increased from 1512082 to 7823340 people in the study period [15]. This implies that the land is consumed at excessive rates and probably in unnecessary amounts as well. The change of the development model towards sprawl is evident in the city of Tehran, particularly in the peripheral fringes. Extensive land occupation, high losses in agricultural, the decrease in urban densities and the high amount of urban bare land expecting for further development are, perhaps, the main signs of the current urban transformation and robust indicators of the new direction taken by the urbanization process.

As urbanization advances, many non-urban hectares disappear. In our study area, however, a high proportion of this new urban land have been categorize in the fertile agricultural and crop lands. In this stage, we overlaid the urban growth map on soil class map that results have shown in Table 2. As summarized in Table 2, from 70835 hectare lands destroyed by urban expansion during study period, 47225 hectare $(66.65 \%)$ belong to the best crop lands; it means 9300 hectare (13.12\%) soil of class I, 22175 hectares $(31.30 \%)$ class II and 15750 hectares (22.23\%) of class III. lands with different classes and fertility degrees (means a mixture of lands in class I, II, III and IV), which are not separated in the map, totally are 19770 hectare (27.9\%) of entire converted lands. Hillside lands that changed to urban uses have area of 2675 hectares (3.77\%) and about 1000 hectares (1.37\%) of lands class I and II are destroyed by kilns around Tehran. As a result, Fig. 2 and Table 2 reveal that over the past five decades the significant increase of built-up land in the study area was mainly at the expense of the most fertile agricultural lands.

Regarding estimation carried out based on some factors like soil class, region, accessibility to water and potential of wheat production in different parts of Iran, if the development of Tehran was more planned and compact or the direction of expansion changed to unfertile and less yielded lands (class IV, V and VI of soil) and the cultivation of land had continued,

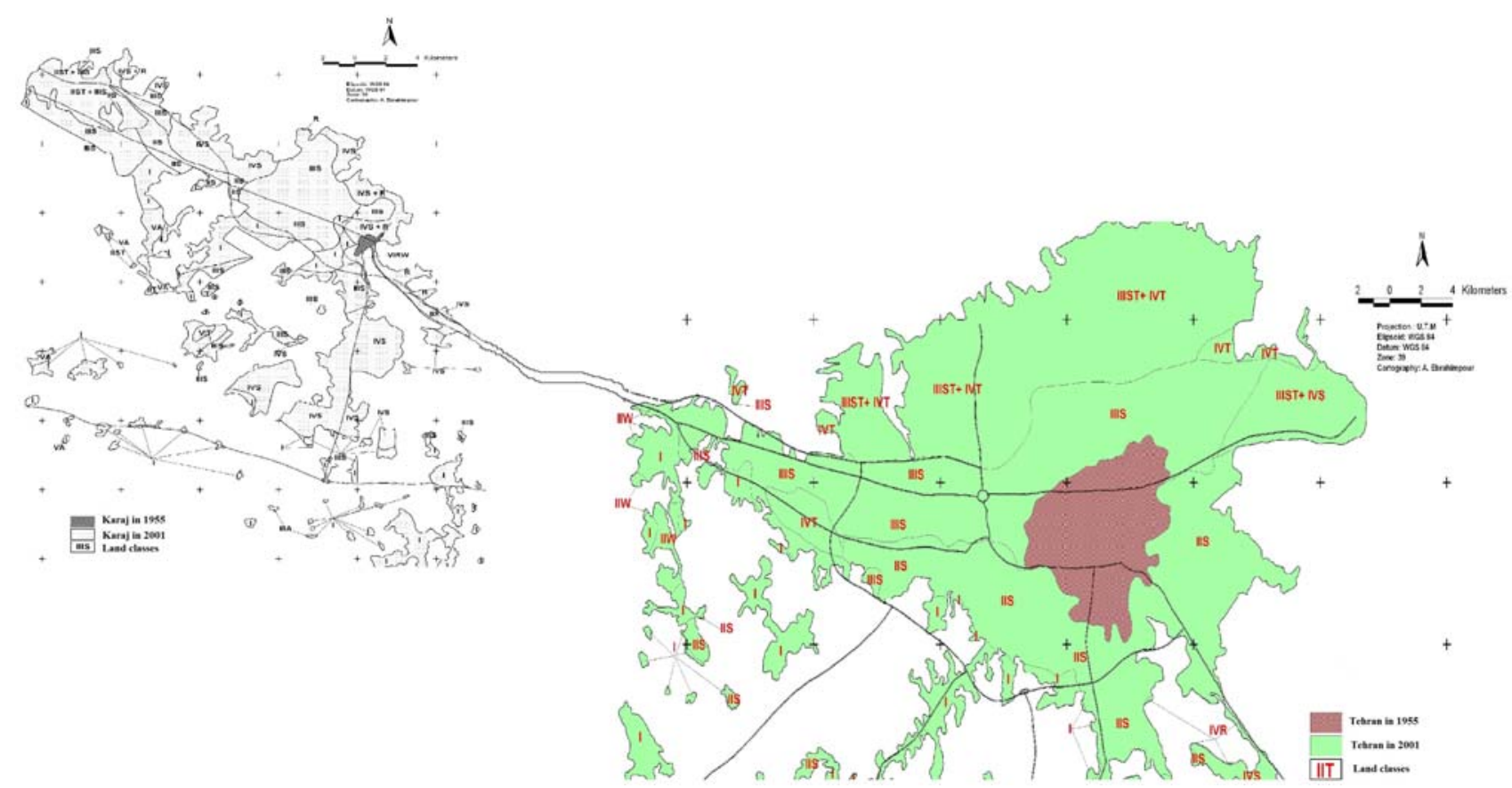

Fig. 2 Map of city border and classes of converted lands in Tehran and Karaj. 
Table 2 Class of area and percentage of destroyed soil resources around Tehran and Karaj.

\begin{tabular}{|c|c|c|c|}
\hline & Soil class & Hectare & Percent \\
\hline \multirow{9}{*}{ Tehran } & $\mathrm{I}$ & 9,300 & 13.12 \\
\hline & II & 22,175 & 31.30 \\
\hline & III & 15,750 & 22.23 \\
\hline & IV & 2,675 & 3.77 \\
\hline & $\mathrm{V}$ & 175 & 0.24 \\
\hline & VI & 15 & 0.02 \\
\hline & Mixed classes (I, II, III and IV) & 19,770 & 27.90 \\
\hline & Refinery & 975 & 1.37 \\
\hline & Total & 70,835 & 100 \\
\hline \multirow{9}{*}{ Karaj } & I & 5,350 & 21.24 \\
\hline & II & 1,350 & 5.36 \\
\hline & III & 7,690 & 30.54 \\
\hline & IV & 6,280 & 24.94 \\
\hline & $\mathrm{V}$ & 655 & 2.60 \\
\hline & VI & 260 & 1.03 \\
\hline & Mixed classes (I, II, III and IV) & 3,175 & 12.60 \\
\hline & $\mathrm{R}$ & 420 & 1.66 \\
\hline & Total & 25,180 & 100 \\
\hline
\end{tabular}

270,000,000 kilograms of wheat could be produced yearly. In addition to wheat production, disrupted land has had the ability of production of cash crops. In explanation about how we reached to this number of wheat production, it should be explained that Iranian Ministry of Cultivation divided whole country into 15 zones. Every zone has its own amount of productivity based on some capabilities such as accessibility to water, surface or underground water, slope, soil type and etc. Furthermore, in each zone, every soil class has a specific ability of productivity that usually calculated in the productivity of wheat. For example, study area (Tehran and Karaj), is in the zone 12. Wheat Yield per hectare in class I in this zone potentially is 4500 kilograms per hectare. Thus we calculated other number based on zone and different soil classes of each and just mentioned the total number.

\subsection{Karaj}

The city of Karaj was a small town between Tehran and Ghazvin, with a population of approximately 14000 residents in 1955. Locating very close to the capital city, and consequently having some facilities, Karaj has attracted plenty of immigrants whose destination is Tehran. Due to dwelling of newcomers, its population increased to 1277552 in 2001 (Iranian Statistic Center, 2009), but urban area increased from 125 to 26000 hectares in the same period (1995-2001). Since Karaj region is one of the richest and most fertile agricultural zones of Iran with having enough water from Karaj dam, its sprawl and expansion during last decades has caused a drastic land use conversion. This scattered occupation of the territory, which is not innovative in form but considerably in magnitude, influences cultivation structure of this region.

From Table 2 it is possible to discern that between 1955 and 2001, an average of 550 hectares of crop lands has lost yearly around city of Karaj, second largest city in Tehran Metropolitan area (TMA). Based on extracted data from pedology map, from entire converted lands in periphery of Karaj, 14390 ha (57.14\%) are calculated as high fertility soils, i.e., 5350 ha (21.24\%) from class I, 1350 ha (5.36\%) from class II, and 7690 ha (30.54\%) from class III. Also area of 6280 ha (24.94) which converted to urban land uses are hillside lands that have been used as pasture (class IV).

Remarkable point in Karaj land use change detection is that proportion of less yielded soils and barren lands, 
class $\mathrm{V}$ and $\mathrm{VI}$ of soil from total converted lands are a little, 2.6 and 1.03 percent respectively. Also, we have to mention that lands with different classes and fertility degrees (means a mixture of different land classes of I, II, III and IV), which are not separated in the map, totally are 3175 hectares $(12.6 \%)$ of converted lands. If the city of Karaj grew more planned and not in the model of sprawl and dispersed development, or development directed to non fertile lands (class IV, V, VI), it could be possible to produce 70000 kilograms of wheat yearly. Therefore, the most disrupted land and soil resources in the evolution of urban sprawl in two largest cities of TMA are from the first three soil classes that had to use for cultivation.

\section{Discussion}

As we presented in the Figures and tables, two cities of Tehran and Karaj are expanding very fast in the outskirt and are experiencing a change towards more dispersed and horizontal rather than vertical growth at the expense of farming and agricultural lands. Even though, according to Ministry of Housing and Urban Planning of Iran, urban planners and governors must try not to use land classes of I, II, III for urban land uses in the process of urbanization and they should give priority to classes of IV, V, VI [16]. But, about two third of entire destroyed land due to urbanization and urban sprawl in these cities are categorized in the best and most fertile lands (classes of I, II, III). According to some other papers carried out in this study area by authors or other researchers, the loss of soil resources is not only adverse effect of urban sprawl in Tehran Metropolitan Area (TMA), but also there are some other negative impacts such as local climate change [17], increase of commute length, increase of gasoline consumption for transportation or some other energy resources and consequently air pollution [18]. If this investigation generalized and carried in the national scale, it will indicate an accelerated process of urbanization and the extent of sprawl and accordingly alarming rate of land use change from Fertile agricultural land to concrete structure of urbanization. Because the United Nations (2004) predicted that this will increase to 80 percent by 2020 . Other countries do not escape from this development and growth model. In this respect, the dispersed form or "urban sprawl", has become a very a remarkable characteristic of urban development worldwide in the last decades [19]. It also has been blamed for many social and environmental ills to the extent that a number of initiatives in North America, such as the "Smart Growth" and "New Urbanism" movements, have made strong appeals to curtail its expansion [20-25]. As it pointed out before, for understanding urban sustainable form, we need to recognize both negative and positive effects of each urban form in terms of social, environmental and economic impacts. Though it is difficult to present one urban model form for all countries and cities with different extents, but we are going to deduce here that current worldwide urban form, urban sprawl, cannot be sustainable urban form absolutely.

\section{Conclusion}

Increasing urbanization of Iran over the last several decades has caused significant increase in urban land use, number of cities and populations of cities. Most Iranian cities are located into or in the vicinity of agricultural lands, only with the purpose of using them. Due to the fast physical development of the cities, these desirable rich agricultural lands are being transformed into urban land uses. Among Iranian urban areas, Tehran Metropolitan Area (TMA) has had a very accelerate rate of population growth caused by many pull factors and land development much more than population. Results obtained from this paper show that two biggest cities of this metropolitan area (Tehran and Karaj which have settled about $80 \%$ of total TMA residents) are expanded more than 100000 hectares over 46 past years. But the expansion and sprawl of these cities is in expenses of fertile agricultural lands, i.e., about two third of entire loss land ( 65 percent) are from class I, II, III in terms of soil fertility and 
productivity. In addition to this, because of topographic restriction for development and construction in the north and east and in some extent in the south of Tehran, future growth will take place in the west of city, where city of Karaj is located. As a result, distance between these two cities will be occupied in close future and a very big and long continuous city or metropolis will emerge. We can conclude that according to findings of this paper about destroyed lands and soil resources resulted from urban sprawl and also referred to consequences of other researchers about its potential negative and irreversible effects for urban sustainability, urban sprawl is seen as one of the potential threats to urban sustainable development.

\section{References}

[1] B. Catalan, D. Sauri and P. Serra, Urban sprawl in the Mediterranean? Patterns of growth and change in the Barcelona Metropolitan Region 1993-2000, Landscape and Urban Planning 85 (20080) 174-184.

[2] C. O. Tong and S. C. Wong, The advantages of a high density, mixed land use, linear urban development, Transportation 24 (1997) 295-307.

[3] H. S. Sudhira, T. V. Ramachandra and K. S. Jagadish, Urban sprawl: metrics, dynamics and modelling using GIS, International Journal of Applied Earth Observation and Geoinformation 5 (2004) 29-39.

[4] S. Zanganeh Shahraki, The Investigation on urban sprawl of Tehran city and its impacts on agriculture lands, Ms Thesis, University of Tehran, 2007. (in Persian).

[5] S. A. Hosseini, The analyzing of Mashhad city sprawl and its effect on the soil and water resources, MA Thesis in Geography and Urban Planning, University of Tehran, 2008. (In Persian)

[6] M. H. Saraie, Multiple patterns of Yazd growth, Quarterly of Geographic Research 84 (2008) 75-98 (in Persian).

[7] H. Ghiumi Mohammadi, An alarm about conversion of agricultural to urban land use: case study, Isfahan, Journal of Water and Soil Resources 14 (2) (2001) 23-28 (in Persian).

[8] R. Farhoudi, S. Zanganeh Shahraki and R. Saed Moucheshi, Spatial distribution of population in Iranian urban system, Quarterly of Geographical Research 68 (2009) 55-68 (in Persian).

[9] P. M. Torrens and M. Alberti, Measuring sprawl, Working paper no. 27, Centre for Advanced Spatial Analysis, University College, London, 2000, available online at: http://www.casa.ac.uk/working papers/.
[10] K. B. Barnes, J. M. Morgan III., M. C. Roberge and S. Lowe, Sprawl development: Its patterns, consequences, and measurement, Towson University, Towson, 2001, available online at: http://www.chesapeake.towson.edu /landscape/urbansprawl/download/Sprawlwhitepaper.pdf.

[11] J. Epstein, K. Payne and E. Kramer, Techniques for mapping suburban sprawl, Photogrammetr. Eng. Remote Sens. 63 (9) (2002) 913-918.

[12] H. Akbari, L. Shea Rose and H. Taha, Analyzing the land cover of an urban environment using high-resolution orthophotos, Landscape Urban Plan 63 (1) (2003) 1-14.

[13] M. A. Cunningham, Accuracy assessment of digitized and classified land cover data for wildlife habitat, Landscape Urban Plan 78 (2006) 217-228.

[14] Iranian Institute of Water and Soil, Categorization of soil resources in different parts of Iran in maps of scale 1:50000, Tehran, Iran, 2005. (in Persian)

[15] Iranian Statistic Center, Census data, Tehran, Iran, 2009. (in Persian)

[16] Ministry of Housing and Urban Planning of Iran, Collection of law and acts of urban planning and development, Sepehr publication, Tehran, Iran, 2000.

[17] Gh. R. Roshan, S. Zanganeh Shahraki, D. Sauri and R. Borna, Urban sprawl and climatic change in Tehran, Iraninan Journal of Environmental Health Science and Engineering 7 (1) (2010) 43-52.

[18] A. Pourahmad, A. Baghvand, S. Zangenehe Shahraki and S. Givehchi, The Impact of Urban Sprawl up on Air Pollution, International Journal of Environmental Research 1 (3) (2007) 252-257.

[19] R. M. Leichenko and W. D. Solecki, Exporting the American dream: The globalization of suburban consumption landscapes, Region. Stud. 39 (2005) 241-253.

[20] K. A. Danielsen, R. E. Lang and W. Fulton, Retracting suburbia: smart growth and the future of housing, Hous. Policy Debate 10 (3) (1999) 513-539.

[21] A. Duany, E. Plater-Zyberk and J. Speck, Suburban Nation: The Rise of Sprawl and the Decline of the American Dream, North Point Press, New York, 2000.

[22] J. A. Dutton, New American Urbanism: Re-forming the Suburban Metropolis, Skira Architecture Library, Milan, 2000.

[23] R. Ewing, Is Los Angeles style desirable? J. Am. Plan. Assoc. 63 (1) (1997) 107-126.

[24] P. Katz, The new urbanism, in: Toward an Architecture of Community, McGraw-Hill, New York, 1994.

[25] J. H. Kunstler, Geography of Nowhere: The Rise and Decline of America's Man-Made Landscape, Touchstone, New York, 1994. 